OPEN ACCESS

Edited by:

Almo Farina

University of Urbino Carlo Bo, Italy

Reviewed by:

Lucille Chapuis,

University of Exeter, United Kingdom

${ }^{*}$ Correspondence:

Rok Šturm

rok.sturm@nib.si

Specialty section:

This article was submitted to

Population, Community,

and Ecosystem Dynamics,

a section of the journal

Frontiers in Ecology and Evolution

Received: 03 December 2021

Accepted: 07 February 2022

Published: 02 March 2022

Citation:

Šturm R, López Díez JJ,

Polajnar J, Sueur $J$ and

Virant-Doberlet M (2022) Is It Time for

Ecotremology?

Front. Ecol. Evol. 10:828503.

doi: 10.3389/fevo.2022.828503

\section{Is It Time for Ecotremology?}

\author{
Rok Šturm ${ }^{1,2 *}$, Juan José López Díez ${ }^{1,2}$, Jernej Polajnar ${ }^{1}$, Jérôme Sueur ${ }^{3}$ and \\ Meta Virant-Doberlet ${ }^{1}$
}

${ }^{1}$ Department of Organisms and Ecosystems Research, National Institute of Biology, Ljubljana, Slovenia, ${ }^{2}$ Department of Biology, Biotechnical Faculty, University of Ljubljana, Ljubljana, Slovenia, ${ }^{3}$ Institut de Systématique, Évolution, Biodiversité (ISYEB), Muséum national d'Histoire naturelle, CNRS, Sorbonne Université, EPHE, Paris, France

Our awareness of air-borne sounds in natural and urban habitats has led to the recent recognition of soundscape ecology and ecoacoustics as interdisciplinary fields of research that can help us better understand ecological processes and ecosystem dynamics. Because the vibroscape (i.e., the substrate-borne vibrations occurring in a given environment) is hidden to the human senses, we have largely overlooked its ecological significance. Substrate vibrations provide information crucial to the reproduction and survival of most animals, especially arthropods, which are essential to ecosystem functioning. Thus, vibroscape is an important component of the environment perceived by the majority of animals. Nowadays, when the environment is rapidly changing due to human activities, climate change, and invasive species, this hidden vibratory world is also likely to change without our notice, with potentially crucial effects on arthropod communities. Here, we introduce ecotremology, a discipline that mainly aims at studying substrate-borne vibrations for unraveling ecological processes and biological conservation. As biotremology follows the main research concepts of bioacoustics, ecotremology is consistent with the paradigms of ecoacoustics. We argue that information extracted from substrate vibrations present in the environment can be used to comprehensively assess and reliably predict ecosystem changes. We identify key research questions and discuss the technical challenges associated with ecotremology studies.

Keywords: ecotremology, monitoring, hidden biodiversity, vibroscape, vibrational communication

\section{INTRODUCTION}

Our awareness of sounds in natural and urban environments has led to the recognition of soundscape ecology (Pijanowski et al., 2011a) and ecoacoustics (Sueur and Farina, 2015). These two interdisciplinary research fields in an non-invasive way increase the understanding of ecological processes and ecosystem dynamics through acoustic monitoring that can assess biodiversity and human impact on terrestrial, freshwater and marine ecosystems (reviewed in Linke et al., 2018; Miksis-Olds et al., 2018; Sugai et al., 2019). However, in contrast to the prevailing general belief that organisms mainly rely on information provided by air-borne or underwater sounds, research over the past decade suggests that substrate-borne vibrations are one of the most prevalent sources of environmental information (Cocroft et al., 2014; Hill et al., 2019). Vibrational signaling is the most common and taxonomically widespread form of mechanical communication (Cocroft and Rodríguez, 2005; Cocroft et al., 2014). Animals can also perceive and use vibrational information 
available in the environment outside of the communication context, for example to detect prey, host or predators (VirantDoberlet et al., 2019). Substrate vibrations can provide relevant information about the environment for plants (Appel and Cocroft, 2014; Mescher and Pearse, 2016) and bacteria (Reguera, 2011). The increased awareness of the importance of substrate vibrations to organisms has recently led to the definition of biotremology (see Table A1), a new field of animal behavior research (Hill and Wessel, 2016; Hill et al., 2019).

Here, we aim to expand biotremology beyond behavioral studies by promoting the concepts of vibroscape and ecotremology. We argue that information on substrate vibrations present in the environment can be useful to comprehensively assess ecosystem functions and propose more effective conservation plans in the future. We first introduce the concepts of vibroscape and ecotremology, highlighting the similarities and differences to soundscape and ecoacoustics. We then identify the key research questions that should be addressed, and finally, we discuss some challenges associated with ecotremology studies and possible applications. In line with our own research and existing literature, we focus primarily on terrestrial habitats.

\section{VIBROSCAPE AND ECOTREMOLOGY-THE CONCEPTS}

\section{Sound and Vibration}

Our intent here is not to delve into the physics of sound and vibration, but to briefly discuss some conceptual issues relevant to understanding the nature of mechanical information in the environment that can be used for ecosystem assessment and surveys.

For the purpose of ecosystem monitoring, the separation between sound and vibration may be surprisingly difficult. Sound and vibration are two terms so commonly used in everyday life that they are generally accepted as distinct. However, the terminology and definition of sound and vibration may differ between physicists, mechanical engineers and biologists (Cremer et al., 2005; Hill, 2008; Hill and Wessel, 2016; Mortimer, 2017; Strauß et al., 2021). Here we follow the biological definition of sound where detection mechanism is important (Hill, 2009; Hill and Wessel, 2016). Both sound and vibration are at the source generated by mechanical vibrations and the energy is transferred through the surrounding medium (air, liquid or solid) by mechanical waves characterized by particle oscillation (Cremer et al., 2005; Hill, 2008, 2009; Caldwell, 2014). In more fluid homogenous media like air and water, mechanical waves propagate as longitudinal compressional (pressure) waves with particle oscillations in the direction of wave propagation and are primarily detected by pressure (or pressure difference) receivers known as ears [but see exceptions in fish (Popper and Hawkins, 2018)]. In solids, various types of mechanical waves relevant to animal behavior propagate at the interface between two media (surface-borne waves) and are received by mechanoreceptors detecting the particle displacement perpendicular to the direction of wave propagation
(Hill, 2008, 2009; Hill and Wessel, 2016; Hill et al., 2019; Strauß et al., 2021). Here, we refer to the former as sound and the latter as vibrations. Energy is also transferred across the interface between two media: the mechanical waves propagating through the air induce particle oscillations in the solid medium with which the air is in contact. Thus, the same source (e.g., a stridulating bushcricket sitting on a plant) simultaneously generates mechanical waves in both surrounding media (air and solid, i.e., plant or ground), both directly by mechanical vibrations of the body and indirectly by a transfer of energy between the two media (Caldwell, 2014; Hill and Wessel, 2016; Figure 1).

The propagation of substrate vibrations through the environment is more complex than the propagation of airor water-borne sound. First, a vibrating source induces in the substrate several different types of mechanical waves simultaneously, while the substrate geometry and material composition influence their transmission properties and frequency dependence (see e.g., Michelsen et al., 1982; Aicher and Tautz, 1990; Barth, 1998; Hill, 2009; Polajnar et al., 2012; Mortimer, 2017; Hawkins et al., 2021). In addition, differences in physical properties within and between plants, with and between soil types, and with and between ground covers make the propagation of vibrations through the habitat highly difficult to predict (Hill, 2009; Elias and Mason, 2014; Strauß et al., 2021). Although the substrate can be any solid surface or object in the environment, the most relevant natural substrates from the perspective of ecosystem monitoring are plants and ground, including river- and seabed (Cocroft and Rodríguez, 2005; Roberts and Elliott, 2017; Hawkins et al., 2021). In the literature, vibrations propagating through the ground are often referred as seismic (e.g., Arnason et al., 2002). The environment has a major impact on the transmission and detectability of vibrational signals: geometry (size and shape) and physical characteristics (density, elasticity) impact signal attenuation and distortion (Hill, 2009; Elias and Mason, 2014; Mortimer, 2017). Although substrate vibrations are generally considered as a short range communication channel, the active space of arthropod vibrational signals on a shrub or tree has been shown to extend up to several meters (McVean and Field, 1996; Barth, 2002). The effective range of seismic signals can even cover kilometers as demonstrated by long-range seismic communication in elephants (Günther et al., 2004; Narins et al., 2016). From the plant on which an insect emits signals, vibrational signals are transmitted to neighboring plants via touching leaves, stems and roots (Šturm et al., 2019) and also across smaller air-gap between plants that are not physically connected (Eriksson et al., 2011; Gordon et al., 2019).

\section{Soundscape and Vibroscape}

Substrate-borne vibrations are ubiquitous in nature (Hill, 2009). Analogous to soundscape (Pijanowski et al., 2011a), vibroscape has been defined as a collection of all vibrations emanating from the environment, that includes biological, geophysical and anthropogenic components (Šturm et al., 2019).

Except some high intensity anthropogenic and geophysical sources (e.g., train, earthquake), vibroscape is hidden from 


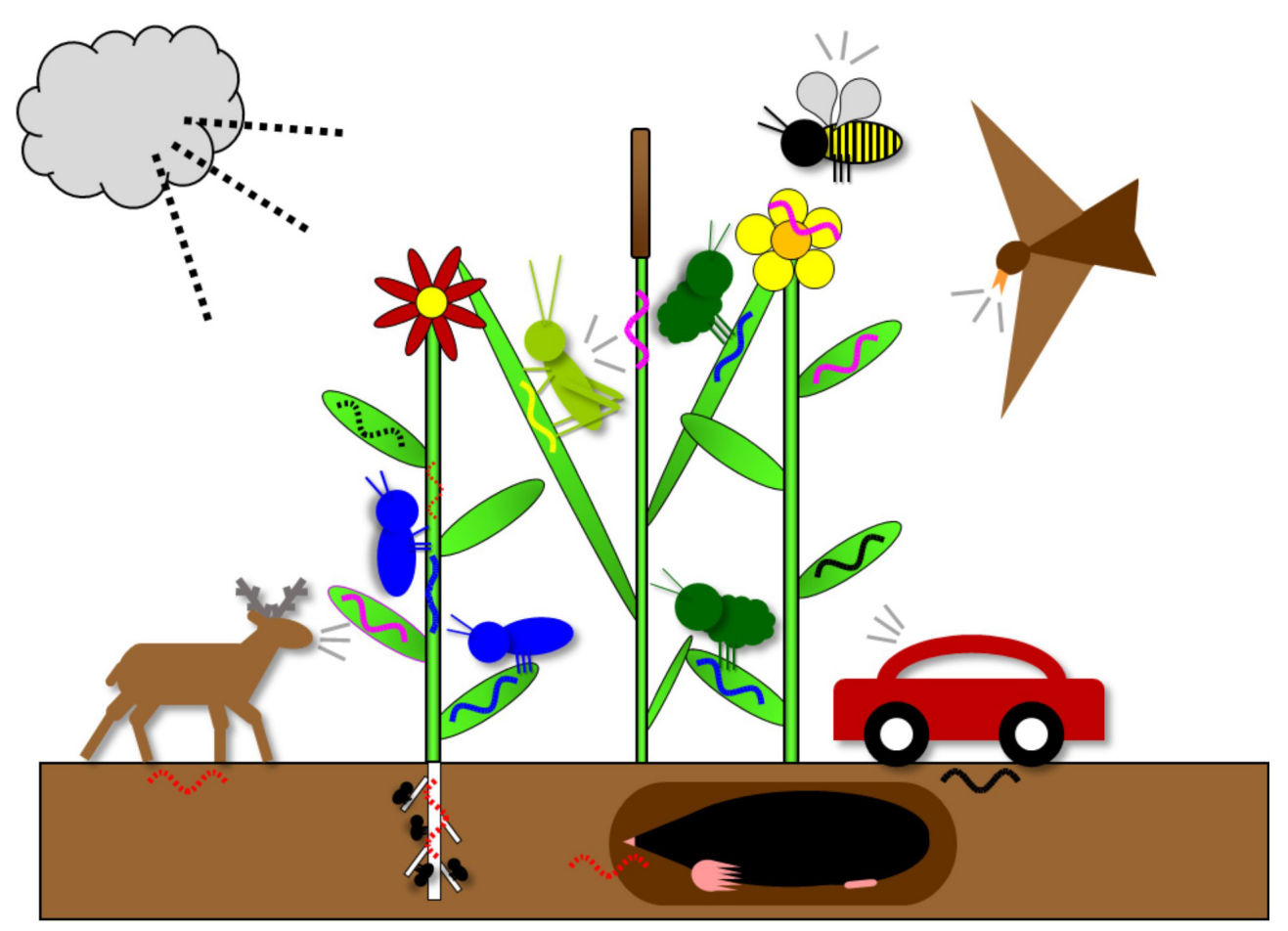

FIGURE 1 | Schematic presentation of sources that can contribute to a vibroscape recorded in a hay meadow habitat. The main source of biological vibrations are vibrations emitted by animals, either during intraspecific vibrational communication (blue waves), or as an incidental by-product of other activities [red dotted waves, vibrations induced by locomotion (walking deer, digging mole, walking insect) and feeding (insect nymphs on the roots)]. Biological component also includes directly (yellow wave, stridulating grasshopper) or indirectly induced vibrational components of air- borne animal sounds (pink waves: stridulating grasshopper, singing bird, calling deer, wing buzzing bee). The main source of geophysical vibrations is wind (black dotted wave). Anthropogenic vibrations (directly and indirectly induced) (black waves) are represented by a car. Other sources not shown (e.g., animals communicating with vibrational signals underground, landing of insects on the plant, rain) also contribute to vibroscape.

human senses and we need to understand it primarily from the perspective of organisms decoding the vibrational information present in the environment. Taking this perspective is challenging due to the size disparity between humans and organisms relying on substrate vibrations, from tiny fruit flies (Drosophilidae) to large elephants. Species-specific ability to generate and detect substrate vibrations results in different spatial scales. For example, for an insect, vibroscape can represent a meadow area of 50 square centimeters, whereas for elephants it can cover an area of several square kilometers.

Regardless of spatial scale, the vibroscape potentially includes more contributing sources than soundscape. It incorporates the sources which may be located above or below ground and may induce vibrations directly by body movements or indirectly by producing sound, whereas only the air-borne component of sound-producing sources contributes to the terrestrial soundscape (Figures 1, 2). Vibroscape characteristics and vibrational communities are largely unexplored but first analyses indicate that terrestrial vibroscapes are dominated by frequencies below $2 \mathrm{kHz}$. This frequency band includes wind vibrations (geophysical vibrations), human-generated vibrations (anthropogenic vibrations), as well as animal signals (biological vibrations) (Šturm et al., 2019, 2021; Figure 2).
It is currently estimated that more than 240,000 arthropod and vertebrate species use vibrational signaling in various intraspecific interactions (Cocroft and Rodríguez, 2005; Uhl and Elias, 2011; Narins et al., 2016).

\section{Ecoacoustics and Ecotremology}

The importance of substrate vibrations in communication and survival of most animals has now been well established (Hill, 2009; Cocroft et al., 2014; Virant-Doberlet et al., 2019). However, the ecological significance of vibroscape has been so far largely overlooked (Šturm et al., 2019, 2021). While ecoacoustics studies sources of air- or water-borne sounds as indicators of ecological processes (Sueur and Farina, 2015), ecotremology aims at recording, monitoring and understanding the vibrations that emanate from natural environments. The theoretical framework on which ecoacoustics is based-the acoustic niche hypothesis $(\mathrm{ANH})$ and the acoustic adaptation hypothesis (AAH) (Sueur and Farina, 2015)-provides the foundation for ecotremology as well. Ecotremology opens up the possibility of monitoring a wide variety of arthropod species that are essential for ecosystem functioning and conservation, but are not accessible through other non-invasive methods. Considering vibroscape is a unique way to monitor neglected but crucial animal biodiversity found in grasslands and bushlands, ecotremology also gives the 

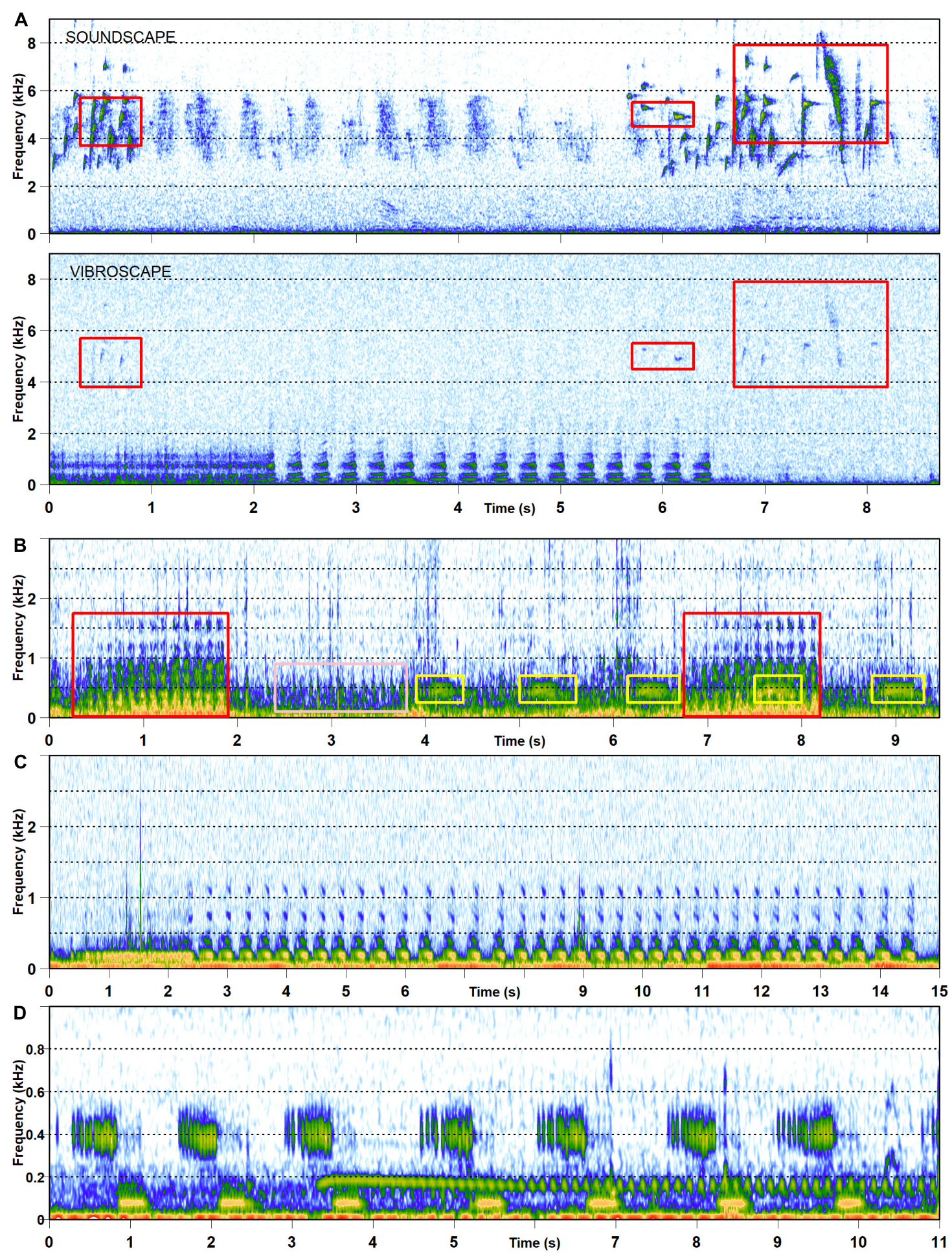

FIGURE 2 | Visualizations of the vibroscape recorded by laser vibrometer in the form of spectrograms. (A) Simultaneous recording of soundscape (above) and vibroscape (below) from Bistra (Slovenia) meadow on July 6, 2021. Vibroscape was recorded on wild strawberry (Fragaria vesca). Red frames indicate bird songs of European goldfinch (Carduelis carduelis) observed on both channels; (B) Vibroscape recorded on herbaceous plant hedge bedstraw (Galium mollugo) in a hay meadow at Bistra (Slovenia) on July 7, 2018. Frames of different color indicate different types of vibrational signal (species unknown). Note strong constant background vibrational noise induced by wind in the frequency range up to $1 \mathrm{kHz}$. (C) Vibroscape recorded from a spider web (from f. Lyniphidae) includes vibrational signals of the Aphrodes bicincta in a hay meadow at Bistra (Slovenia) on July 14, 2020. (D) Vibroscape recorded on a dogwood bush (Cornus sanguinea) at Bistra on June 20, 2019 (signallers unknown). All spectrograms obtained with the R package seewave (Sueur et al., 2008). 
opportunity to approach in a passive way the ecology of unique populations, communities and landscapes.

\section{ECOTREMOLOGY-KEY RESEARCH QUESTIONS TO BE ADDRESSED}

The research questions and applications of ecotremology are largely the same as those of ecoacoustics (Sueur and Farina, 2015; Farina and Gage, 2017; Farina, 2018; Linke et al., 2018). However, because vibroscape studies are still in their infancy and due to some fundamental differences between environmental sound and vibration, several specific research questions should be addressed first.

\section{Spatial and Temporal Variation in Vibroscape}

The extent and significance of spatial and temporal variation are fundamental questions that should be resolved before the implementation of ecotremological ecosystem monitoring, reflecting our lack of personal experience of the natural vibratory world. Due to heterogeneity of the substrate that affects damping and selective frequency filtering, the amplitude of emitted vibrational signals may be reduced below detection level $10 \mathrm{~cm}$ away from the plant on which an arthropod is signaling. As a consequence, the recorded vibroscape may change substantially and unpredictably over a few centimeters (Šturm et al., 2019, 2021). In such a situation, any vibration sensor will pick up signals from an area that is several order of magnitude smaller than with microphones, downscaling the spatial range of observation.

Vibroscape may be plant species-specific due to the geometry and transmission properties of the plant, and the plant-dwelling animals that can be host specific inside and on the plant. Furthermore, spatial position of individual plant within the habitat may crucially influence the recorded vibroscape due to neighboring plants with their specific characteristics or abiotic conditions (e.g., sunny or shady, wind-exposed or sheltered position) (Šturm et al., 2021).

Vibroscape composition also shows substantial diel and seasonal changes (McNett et al., 2010; Šturm et al., 2021). To develop adequate sampling design, studies of signal transmission on different substrates within the natural habitats, including sediments in aquatic environments (Roberts and Elliott, 2017; Hawkins et al., 2021) along with a comprehensive analysis of variation in vibroscape characteristics over short distances within a single field-site and long-term 24 -h recordings are vital.

In comparison with ecoacoustic studies, vibroscape monitoring lags far behind due to technical challenges associated with field recordings (Šturm et al., 2019) and several technical issues should be resolved before a general ecotremological approach can be developed. Autonomous vibration recorders for vibroscape monitoring are currently not available and the cost of equipment for registering substrate vibrations over an array of multiple sensors, as usually deployed for soundscape analyses, may be a limiting factor and solutions should be sought to develop inexpensive vibroscape recording approaches.
While affordable seismic sensors such us geophones are available (e.g., Reinwald et al., 2021), recording from substrates like plants requires a different recording approach. Portable laser vibrometers are the most sensitive and avoid the problem of mass loading, but are costly and complex. However, there are other less expensive sensors available (Nieri et al., 2022). Although accelerometers are likely to be less suitable to reliably attach to herbaceous plants and grasses, they currently hold the most promising solution for recording with an array of sensors.

\section{Characterization of Vibroscape and Vibrational Communities in Different Habitats and Ecosystems}

The only existing vibroscape study focused on a temperate hay meadow at a single site (Šturm et al., 2021). Before generalizations can be made, comprehensive comparative studies of vibroscape recorded on different substrates and in different habitats and ecosystems, including aquatic environments, are needed, not only to characterize the biological component as mentioned above, but also the contributions of geophysical and anthropogenic components.

Ecotremology appears as a challenging field of research. First of all, the number of sources is relatively high, implying an additional level of complexity due to rich communities. Second, due to the complex pattern of vibration propagation through solids under field conditions, the degradation of signals is unpredictable with particularly important frequency and temporal changes (Michelsen et al., 1982; Casas et al., 2007; Polajnar et al., 2012; Mortimer, 2017; Brandt et al., 2018; Šturm et al., 2019). Third, ecotremology cannot refer to a public sample libraries as they exist for bird, amphibian or mammal sounds. The lack of a library hinders the manual or automatic identification of vibrational sources. The establishment of a comprehensive public library of vibrational signals that would include not only reference signals recorded in the laboratory, but also signals recorded on different natural substrates under different field conditions, is essential to the implementation of ecotremological studies. Ideally, such library should also include vibrational components of air-borne sounds and incidental vibrations.

Selection pressures pertinent to AAH and ANH, respectively, associated with evolutionary constraints on acoustic signals (e.g., Sueur and Farina, 2015; Farina and James, 2016; Krause and Farina, 2016) are also relevant to the processes underlying the observed structure and complexity of vibroscape. Because the effects of the physical environment on the evolution of vibrational signals and signaling strategies are especially strong (Cocroft et al., 2010; Endler, 2014), studies of the structure and dynamics of vibrational communities are likely to provide good model systems for the effects of adaptation and competition on partitioning of the communication channel (Šturm et al., 2021).

\section{Relation Between Soundscape and Vibroscape}

Although vibroscape includes also the vibrational component of air-borne sounds, it is not possible to predict vibroscape 
richness and structure of a particular habitat from its soundscape characteristics (Šturm et al., 2021). The variety of potential sources contributing to the vibroscape composition (Figure 1) might also suggest that the vibroscape could be richer than the soundscape. However, this is not necessarily the case and the relation certainly depends on habitat, season and diel dynamics. Simultaneous recordings of soundscape and vibroscape should determine complementary mechanical information available in the environment and provide crucial information for appropriate sampling design.

\section{Link Between Vibroscape Composition and Ecosystem State}

Vibroscape has remained "out of sight, out of mind" until recently and there is no existing information about the composition and structure of vibroscape in the past. Current natural vibrational communities may already have been altered due to habitat loss and fragmentation, biological invasion, climate change and anthropogenic noise. Although there is so far no information on the impact of human activities on vibroscapes, field studies of the effects of anthropogenic vibrations showed negative effects on animal behavior (Shier et al., 2012; Day et al., 2019; Phillips et al., 2020; Mortimer et al., 2021; Roberts and Howard, 2022). The recording of pristine and disturbed vibroscapes appears as a prerequisite for future work; however, there is also a need to build reference libraries and baseline information to assess the possible future changes of vibroscapes.

Acoustic indices are often used to characterize soundscape and acoustic communities or to find proxies of local biodiversity (e.g., Sueur et al., 2014; Gasc et al., 2015; Buxton et al., 2018; Eldridge et al., 2018). In ecotremology, the relationship between rich biological vibroscape component and ecosystem state has not yet been established and is not likely to be straightforward. Indices developed to characterize soundscape might not be directly applicable to vibroscapes. In addition, the indices have been shown to be sensitive to background noise when soundscape monitoring has a low signal-to-noise ratio (e.g., Desjonquères et al., 2015). As a preliminary test, we compared the hay meadow vibroscape recorded at different times of the day, when vibrational signaling activity was the highest (mid-day) and the lowest (midnight). We could not find any consistent correlation between aurally and visually determined richness and abundance of vibrational signals and spectral entropy $H f$, Acoustic Complexity Index ACI (both calculated in frequency range from $200 \mathrm{~Hz}$ to $4,000 \mathrm{~Hz}$ ), the envelope energy $M$, Acoustic Entropy Index $H$ and Acoustic Complexity Index ACI (both calculated in frequency range from 0 to $20,000 \mathrm{~Hz}$ ). However, this initial work does not preclude that other indices might perform better and could be used for a rapid vibroscape assessment in the future.

\section{DISCUSSION}

In contrast to terrestrial soundscapes, which can be perceived and recorded in everyday life humans have no personal experience with natural vibroscapes. The sensory barrier that isolates the vibroscapes from human perception greatly limits both popular and scientific interests in vibroscape. However, there is no good reason to assume a forest soundscape is more important than a meadow vibroscape. Recordings of deep-sea soundscapes have proved that previously inaccessible sounds can greatly attract the attention of large audiences, including scientists, artists and citizens (Duarte et al., 2021). The development of low-cost and reliable recording equipment suitable for long-term unsupervised field-recordings in research programs, but also for opportunistic recordings is necessary to increase interest in this hidden form of biodiversity.

As in ecoacoustic studies, vibroscape recordings may generate a large amount of raw data reaching several TB very quickly (Šturm et al., 2019). Manual identification is highly timeconsuming, so that large datasets cannot be thoroughly processed by a small number of observers and automated species identification and diversity assessment is needed. At present, manual identification and assignation of vibrational signals by listening and visualization of spectrograms is still challenging due to unpredictable changes in signal structure during transmission, high levels of vibrational noise overlapping the frequency range of vibrational signals, and the lack of reference libraries. The great majority of vibrational signals are unknown, so it can be challenging for an inexperienced listener to distinguish signals from incidental vibrations caused by locomotion or feeding (Šturm et al., 2019). Computational methods for automatic classification and identification of vibrational signals have not yet been tested on field recordings (Korinšek et al., 2019; Šturm et al., 2019, 2021). Nevertheless, even taking into account specific challenges encountered in vibroscape recordings, automatic identification of signals should be possible using recent AI techniques such as convolutional neural networks applied to spectrogram images (Stowell et al., 2019). This option will be possible only if the identification models can be trained with annotated datasets. This again underlines the need of expert and shared libraries.

Seismology is a well-established discipline (e.g., Lecocq et al., 2020) and therefore it is not surprising that it has already provided the first applications of ecotremology in monitoring elephants either by vibrational component of their infra-sound vocalizations or by incidental vibrations induced by locomotion (Wood et al., 2005; Mortimer et al., 2018; Parihar et al., 2021; Reinwald et al., 2021). The latter approach also allows differentiating between large mammal species (Wood et al., 2005). Substrate vibrations created by gunshots could also be invaluable in monitoring poaching (Mortimer et al., 2018).

Monitoring plant-dwelling arthropods provides more challenging application, but nevertheless a preliminary study showed that species-specific vibrational signals of insect pests could be identified in the vibroscape recorded in the vineyard (Akassou, 2021). Monitoring insects through vibroscape analysis could provide important information on the dynamics of insect populations that have been shown to be in severe decline, threating the state of ecosystems and, as consequence, human society (e.g., Wagner, 2020; Miller, 2021; Wagner et al., 2021). 


\section{CONCLUSION}

Vibrational signaling is the most common form of mechanical communication. Although substrate vibrations provide a rich and reliable source of information to the majority of animals, humans have so far overlooked vibroscape as an essential element of the natural environment that can have important effects on ecological processes and ecosystem dynamics. Several key technical challenges will have to be resolved, before such approach can be implemented in the monitoring. We believe that with the increased awareness about vibroscape and the growing research interest and demand for technical solutions, the implementation of ecotremological monitoring will be feasible within the next decade. We encourage researchers, artists and citizens to incorporate ecotremology into their projects to gain better awareness and knowledge of hidden vibroscapes.

\section{REFERENCES}

Aicher, B., and Tautz, J. (1990). Vibrational communication in the fiddler crab. Uca pugilator. J. Comp. Physiol. A. 166, 345-353.

Akassou, I. (2021). Novel approaches to study vibrational signalling of insects. [PhD Thesis] Trento TN: University of Trento. .

Appel, H. M., and Cocroft, R. B. (2014). Plants respond to leaf vibrations caused by insect herbivore chewing. Oecologia 175, 1257-1266. doi: 10.1007/s00442-0142995-6

Arnason, B. T., Hart, L. A., and O'Connel-Rodwell, C. E. (2002). The properties of geophysical fields and their effects on elephants and other animals. J. Comp. Psychol. 116, 123-132. doi: 10.1037/0735-7036.116.2.123

Barth, F. G. (1998). "The vibrational sense in spiders," in Comparative Hearing: Insects, eds R. R. Hoy, A. N. Popper, and R. Pay (New York: Springer), 228-278. doi: 10.1007/978-1-4612-0585-2_7

Barth, F. G. (2002). A Spider's World: Senses and Behavior. Heidelberg: Springer Verlag.

Brandt, E. E., Kelley, J. P., and Elias, D. O. (2018). The temperature alters multimodal signalling and mating success in an ectoderm. Behav. Ecol. Sociobiol. 72:191.

Buxton, R. T., McKenna, M. F., Clapp, M., Meyer, E., Stabenau, E., Angeloni, L. M., et al. (2018). Efficacy of extracting indices from large-scale acoustic recordings to monitor biodiversity. Conser. Biol. 32, 1174-1184. doi: 10.1111/cobi.13119

Caldwell, M. S. (2014). "Interactions between airborne sound and substrate vibration in animal communication," in Studying Vibrational Communication, eds R. B. Cocroft, M. Gogala, P. S. M. Hill, and A. Wessel (Berlin: Springer Verlag), 65-92. doi: 10.1016/j.cub.2012.09.042

Casas, J., Magal, C., and Sueur, J. (2007). Dispersive and non-dispersive waves through plants: implications for arthropod vibratory communication. Proc. $R$. Soc. B Biol. Sci. 274, 1087-1092. doi: 10.1098/rspb.2006.0306

Cocroft, R. B., Gogala, M., Hill, P. S. M., and Wessel, A. (2014). "Fostering research in a rapidly growing field," in Studying Vibrational Communication, eds R. B. Cocroft, M. Gogala, P. S. M. Hill, and A. Wessel (Berlin: Springer Verlag), 3-12.

Cocroft, R. B., and Rodríguez, R. L. (2005). The behavioral ecology of insect vibrational communication. BioScience 55, 323-334. doi: 10.1641/00063568(2005)055[0323:TBEOIV]2.0.CO;2

Cocroft, R. B., Rodríguez, R. L., and Hunt, R. E. (2010). Host shifts and signal divergence: mating signals covary with host use in a complex of specialized plant-feeding insects. Biol. J. Linn. Soc. 99, 60-72.

Cremer, L., Heckl, M., and Petersson, B. A. T. (2005). Structure-Borne Sound. Berlin: Springer-Verlag.

Day, R. D., McCauley, R. D., Fitzgibbon, Q. P., Hartmann, K., and Semmens, J. M. (2019). Seismic air guns damage rock lobster mechanosensory organs and

\section{DATA AVAILABILITY STATEMENT}

The raw data supporting the conclusions of this article will be made available by the authors, without undue reservation.

\section{AUTHOR CONTRIBUTIONS}

All authors listed have made a substantial, direct, and intellectual contribution to the work, and approved it for publication.

\section{FUNDING}

This work was supported by the Slovenian Research Agency (Javna agencija za raziskovalno dejavnost Republike Slovenije) (research core funding P1-0255, research project J1-8142 and J1-3016 and Ph.D. fellowships awarded to RŠ and JL).

impair righting reflex. Proc. R. Soc. B 286:20191424. doi: 10.1098/rspb.2019. 1424

Desjonquères, C., Rybak, F., Depraetere, M., Gasc, A., Le Viol, I., Pavoine, S., et al. (2015). First description of underwater acoustic diversity in three temperate ponds. PeerJ 3:e1393. doi: 10.7717/peerj.1393

Duarte, C. M., Chapuis, L., Collin, S. P., Costa, D. P., Devassy, R. P., Eguiluz, V. M., et al. (2021). The soundscape of the Anthropocene Ocean. Science 371:eaba4658. doi: 10.1126/science.aba4658

Eldridge, A., Guyot, P., Moscoso, P., Johnston, A., Eyre-Walker, Y., and Peck, M. (2018). Sounding out ecoacoustic metrics: Avian species richness is predicted by acoustic indices ion temperate but not tropical forests. Ecol. Indic. 95, 939-952. doi: 10.1016/j.ecolind.2018.06.012

Elias, D. O., and Mason, A. C. (2014). “The role of wave and substrate heterogeneity in vibratory communication; practical issues in studying the effect of vibratory environment in communication," in Studying Vibrational Communication, eds R. B. Cocroft, M. Gogala, P. S. M. Hill, and A. Wessel (Berlin: Springer Verlag), 215-247.

Endler, J. A. (2014). "The emerging field of tremology," in Studying Vibrational Communication, eds R. B. Cocroft, M. Gogala, P. S. M. Hill, and A. Wessel (Berlin: Springer Verlag).

Eriksson, A., Anfora, G., Lucchi, A., Virant-Doberlet, M., and Mazzoni, V. (2011). Inter-plant vibrational communication in a leafhopper insect. PLoS One 6:e19692. doi: 10.1371/journal.pone.0019692

Farina, A. (2018). Perspectives in ecoacoustics: a contribution to defining a discipline. J. Ecoacoust 2, 1-1.

Farina, A., and Gage, S. H. (2017). "Ecoacoustics: A new science," in Ecoacoustics, eds A. Farina and S. H. Gage (Hoboken: Wiley), 1-11. doi: 10.1002/ 9781119230724.ch1

Farina, A., and James, P. (2016). The acoustic communities: Definition, description and ecological role. BioSystems 147, 11-20. doi: 10.1016/j.biosystems.2016.05. 011

Gasc, A., Pavoine, S., Lellouch, L., Gandcolas, P., and Sueur, J. (2015). Acoustic indices for biodiversity assessments: analyses of bias based on simulated bird assemblages and recommendations for field surveys. Biol. Conserv. 191, 306312 .

Gordon, S. D., Tiller, B., Windmill, J. F. C., Krugner, R., and Narins, P. M. (2019). Transmission of the frequency components of the vibrational signal of the glassy-winged sharpshooter. Homalodisca vitripennis, within and between grapevines. J. Comp. Physiol. A 205, 783-791. doi: 10.1007/s00359-01901366-w

Günther, R. H., O'Connell-Rodwell, C. E., and Klemperer, S. L. (2004). Seismic waves from elephant vocalizations: a possible communication mode? Geophys. Res. Lett. 31:L11602, 
Hawkins, A. D., Hazelwood, R. A., Popper, A. N., and Macey, P. C. (2021). Substrate vibrations and their potential effects upon fishes and invertebrates. J. Acoust. Soc. Am. 149, 2782-2790. doi: 10.1121/10.0004773

Hill, P. S. M. (2008). Vibrational Communication in Animals. Cambridge, MA: Harvard University Press.

Hill, P. S. M. (2009). How do animals use substrate-borne vibrations as an information source? Naturwissenschaften 96, 1355-1371. doi: 10.1007/s00114009-0588-8

Hill, P. S. M., Virant-Doberlet, M., and Wessel, A. (2019). "What is biotremology?, in Biotremology - Studying Vibrational Behavior, eds P. S. M. Hill, R. LakesHarlan, V. Mazzoni, P. M. Narins, M. Virant-Doberlet, and A. Wessel (Berlin: Springer Verlag), 15-25.

Hill, P. S. M., and Wessel, A. (2016). Biotremology. Curr. Biol. 26, R181-R191.

Korinšek, G., Tuma, T., and Virant-Doberlet, M. (2019). “Automated vibrational signal recognition and playback," in Biotremology - Studying Vibrational Behavior, eds P. S. M. Hill, R. Lakes-Harlan, V. Mazzoni, P. M. Narins, M. Virant-Doberlet, and A. Wessel (Berlin: Springer Verlag), 149-173. doi: 10. 1007/978-3-030-22293-2_9

Krause, B., and Farina, A. (2016). Using ecoacoustic methods to survey the impacts of climate change on biodiversity. Biol. Conserv. 195, 245-254. doi: 10.13287/j. 1001-9332.202103.032

Lecocq, T., Hicks, S. P., Van Noten, K., van Wijk, K., Koelemeijer, P., De Plaen, R. S. M., et al. (2020). Global quieting of high-frequency seismic noise due to COVID-19 pandemic lockdown measures. Science 369, 1338-1343. doi: 10. $1126 /$ science.abd2438

Linke, S., Gifford, T., Desjonquéres, C., Tonolla, D., Aubin, T., Barclay, L., et al. (2018). Freshwater ecoacoustics as a tool for continuous ecosystem monitoring. Front. Ecol. Environ. 16:231-238. doi: 10.1002/fee. 1779

Mcloughlin, P. M., Stewart, R., and McElligott, A. G. (2019). Automated bioacoustics: methods in ecology and conservation and their potential for animal welfare monitoring- J. R. S. Interface 16:20190225. doi: $10.1098 /$ rsif 2019.0225

McNett, G. D., Luan, L. H., and Cocroft, R. B. (2010). Wind-induced noise alters signaller and receiver behaviour in vibrational communication. Behav. Ecol. Sociobiol. 64, 2043-2051.

McVean, A., and Field, L. H. (1996). Communication by substratum vibration in the New Zealand tree weta Hemideina femorata (Stenopelmatidae: Orthoptera). J. Zool. 239, 101-122.

Mescher, M. C., and Pearse, I. S. (2016). Communicative interactions involving plants: information, evolution and ecology. Curr. Opin. Plant Biol. 32, 69-76. doi: 10.1016/j.pbi.2016.06.015

Michelsen, A., Fink, F., Gogala, M., and Traue, D. (1982). Plants as transmission channels for insect vibrational songs. Behav. Ecol. Sociobiol. 11, 269-281.

Miksis-Olds, J. L., Marin, B., and Tyack, P. L. (2018). Exploring the ocean through soundscapes. Acoust. Today 14, 26-34.

Miller, Z. J. (2021). What's the buzz about? Progress and potential of acoustic monitoring technologies for investigation bumble bees. IEEE Instrum. Meas. Mag. 24, 21-29. doi: 10.1109/mim.2021.9549234

Mortimer, B. (2017). Biotremology: do physical constraints limit the propagation of vibrational information. Anim. Behav. 130, 165-174. doi: 10.1016/j.anbehav. 2017.06.015

Mortimer, B., Lake Rees, W., Koelemeijer, P., and Nissen-Meyer, T. (2018). Classifying elephant behaviour through seismic vibrations. Curr. Biol 28, R547R548. doi: 10.1016/j.cub.2018.03.062

Mortimer, B., Walker, J. A., Lolchuragi, D. S., Reinwald, M., and Daballen, D. (2021). Noise matters: elephants show risk-avoidance behaviour in response to human-generated seismic cues. Proc. R. Soc. B 288:20210774. doi: 10.1098/rspb. 2021.0774

Narins, P. M., Stoeger, A. S., and O'Connel-Rodwell, C. (2016). “Infrasonic and yeismic communication in the vertebrates with special emphasis on the Afroteria: an update and future directions," in Vertebrate Sound Production and Acoustic Communication, eds R. A. Suthers, W. T. Fitch, R. R. Fay, and A. N. Popper (Heildelberg: Springer Verlag), 191-227. doi: 10.1007/978-3-31927721-9_7

Nieri, R., Michael, S. C. J., Pinto, C. F., Orquizo, O. N., Appel, H. M., and Cocroft, R. B. (2022). "Inexpensive methods for detecting and reproducing substrateborne vibrations: advantages and limitations," in Biotremology: Physiology,
Ecology and Evolution, eds P. S. M. Hill, V. Mazzoni, N. Stritih-Peljhan, M. Virant-Doberlet, and A. Wessel (Heildelberg: Springer Verlag).

Parihar, D. S., Ghosh, R., Akula, A., Kumar, S., and Sardana, H. K. (2021). Seismic signals analysis for the characterisation of elephant movements in a forest environment. Ecol. Inform. 64:101329.

Phillips, M. E., Chio, G., Hall, C. L., Hofstede, H. M., and Howard, D. R. (2020). Seismic noise influence brood size dynamics in a subterranean insect with biparental care. Animal Behav. 161, 15-22.

Pijanowski, B. C., Villanueva-Rivera, L. J., Dumyahn, S. L., Farina, A., Krause, B. L., Napoletano, B. M., et al. (2011a). Soundscape ecology: the science of sound and landscape. BioScience 61, 203-216.

Pijanowski, B. C., Farina, A., Gage, S. H., Dumyahn, S. L., and Krause, B. L. (2011b). What is soundscape ecology? An introduction and overview of an emerging new science. Landsc. Ecol. 26, 1213-1232.

Polajnar, J., Svenšek, D., and Čokl, A. (2012). Resonance in herbaceous plant stems as a factor in vibrational communication of pentatomid bugs (Heteroptera: Pentatomidae). J. R. Soc. Interface 9, 1898-1907. doi: 10.1098/rsif.2011. 0770

Popper, A. N., and Hawkins, A. D. (2018). The importance of particle motion to fishes and invertebrates. J. Acoust. Soc. Am. 143:470. doi: 10.1121/1.502 1594

Reguera, G. (2011). When microbial conversations get physical. Trends Microbiol. 19, 105-113. doi: 10.1016/j.tim.2010.12.007

Reinwald, M., Moseley, B., Szenicer, A., Nissen-Meyer, T., Odour, S., Vollrath, F., et al. (2021). Seismic localization of elephant rumbles as a monitoring approach. J. R. Soc. Interface 18:20210264. doi: 10.1098/rsif.2021.0264

Roberts, L., and Elliott, M. (2017). Good or bad vibrations? Impacts of anthropogenic vibration on the marine epibenthos. Sci. Total Environ. 595, 255-268. doi: 10.1016/j.scitotenv.2017.03.117

Roberts, L., and Howard, D. R. (2022). "Substrate-borne Vibrational Noise in the Anthropocene: from land to sea," in Biotremology: Physiology, Ecology and Evolution, eds P. S. M. Hill, V. Mazzoni, N. Stritih-Peljhan, M. Virant-Doberlet, and A. Wessel (Berlin: Springer Verlag).

Sueur, J., Aubin, T., and Simonis, C. (2008). Seewave: a free modular tool for sound analysis and synthesis. Bioacoustics 18, 213-226. doi: 10.1080/09524622.2008. 9753600

Shier, D. M., Lea, A. J., and Owen, M. A. (2012). Beyond masking: endangered Stephen's kangaroo rats respond to traffic noise with foot drumming. Biol. Conserv. 150, 53-58. doi: 10.1016/j.biocon.2012.03.007

Stowell, D., Wood, M. D., Pamuła, H., Stylianou, Y., and Glotin, H. (2019). Automatic acoustic detection of birds through deep learning: the first Bird Audio Detection challenge. Methods Ecol. Evol. 10, 368-380. doi: 10.1111/2041210x.13103

Strauß, J., Stritih-Peljhan, N., Nieri, R., Virant-Doberlet, M., and Mazzoni, V. (2021). Communication by substrate-borne mechanical waves in insects: From basic to applied biotremology. Adv. Insect. Physiol. 61, 189-307. doi: 10.1016/ bs.aiip.2021.08.002

Šturm, R., Polajnar, J., and Virant-Doberlet, M. (2019). "Practical issues in studying vibroscape and biotic noise," in Biotremology - Studying Vibrational Behavior, eds P. S. M. Hill, R. Lakes-Harlan, V. Mazzoni, P. M. Narins, M. VirantDoberlet, and A. Wessel (Berlin: Springer Verlag), 125-148. doi: 10.1007/9783-030-22293-2 8

Šturm, R., Rexhepi, B., López Díez, J. J., Blejec, A., Polajnar, J., Sueur, J., et al. (2021). Hay meadow vibroscape and interactions within insect vibrational community. iScience 24:103070. doi: 10.1016/j.isci.2021.103070

Sueur, J., and Farina, A. (2015). Ecoacoustics: the ecological investigation and interpretation of environmental sound. Biosemiotics 8, 493-502.

Sueur, J., Farina, A., Gasc, A., Pieretti, N., and Pavoine, S. (2014). Acoustic indices for biodiversity assessment and landscape investigation. Acta Acoust. united Acoustica 100, 772-781. doi: 10.3813/aaa.918757

Sugai, L. S. M., Silva, T. S. F., Ribeiro, J. W., and Llusia, D. (2019). Terrestrial passive acoustic monitoring; review and perspectives. BioScience 69, 15-25. doi: 10.1093/biosci/biy147

Uhl, G., and Elias, D. O. (2011). “Communication,” in Spider Behaviour, ed. M. E. Herberstein (Cambridge: Cambridge University Press), 127-189.

Virant-Doberlet, M., Kuhelj, A., Polajnar, J., and Šturm, R. (2019). Predator-prey interactions and eavesdropping in vibrational communication networks. Front. Ecol. Evol. 7:203. doi: 10.3389/fevo.2019.00203 
Wagner, D. L. (2020). Insect declines in the Anthropocene. Annu. Rev. Entomol. 65, 457-480. doi: 10.1146/annurev-ento-011019-025151

Wagner, D. L., Grames, E. M., Forister, M. L., Berenbaum, M. R., and Stopak, D. (2021). Insect Decline in Anthropoecen: Death by a thousand cuts. Proc. Natl. Acad. Sci. USA 118:e2023989118. doi: 10.1073/pnas.2023989118

Wood, J. D., O'Connell-Rodwell, C. E., and Klemperer, S. L. (2005). Using seismic sensors to detect elephants and other large mammals: a potential census technique. J. Appl. Ecol. 42, 587-594. doi: 10.1111/j.1365-2664.2005. 01044.x

Conflict of Interest: The authors declare that the research was conducted in the absence of any commercial or financial relationships that could be construed as a potential conflict of interest.
Publisher's Note: All claims expressed in this article are solely those of the authors and do not necessarily represent those of their affiliated organizations, or those of the publisher, the editors and the reviewers. Any product that may be evaluated in this article, or claim that may be made by its manufacturer, is not guaranteed or endorsed by the publisher.

Copyright $\odot 2022$ Šturm, López Díez, Polajnar, Sueur and Virant-Doberlet. This is an open-access article distributed under the terms of the Creative Commons Attribution License (CC BY). The use, distribution or reproduction in other forums is permitted, provided the original author(s) and the copyright owner(s) are credited and that the original publication in this journal is cited, in accordance with accepted academic practice. No use, distribution or reproduction is permitted which does not comply with these terms. 


\section{APPENDIX}

TABLE A1 | Table of relevant terms as used in the main text with their definitions.

\begin{tabular}{|c|c|c|}
\hline Term & Definition & References \\
\hline Vibration & Different types of waves on the boundary between two distinct media & Hill and Wessel, 2016 \\
\hline Biotremology & The study of mechanical communication by surface-borne waves & Hill and Wessel, 2016 \\
\hline Vibroscape & A collection of biological, geophysical and anthropogenic vibrations emanating from a given landscape & Šturm et al., 2019 \\
\hline Ecotremology & Discipline studying substrate-born vibrations for unraveling ecological processes & This paper \\
\hline Sound & Purely longitudinal wave in homogeneous medium & Hill and Wessel, 2016 \\
\hline \multirow[t]{2}{*}{ Bioacoustics } & Study of the production, transmission and reception of animal sounds & Mcloughlin et al., 2019 \\
\hline & Study of mechanical communication by acoustic waves & Hill and Wessel, 2016 \\
\hline Soundscape & $\begin{array}{l}\text { Collection of biological, geophysical and anthropogenic sounds that emanate from a landscape and which } \\
\text { vary over space and time }\end{array}$ & Pijanowski et al., 2011b \\
\hline Ecoacoustics & Ecological investigation and interpretation of environmental sound & Sueur and Farina, 2015 \\
\hline
\end{tabular}

